Article

\title{
Analysis of Worldwide Research Trends on the Impact of Artificial Intelligence in Education
}

\author{
Seungsu Paek ${ }^{1}$ and Namhyoung Kim ${ }^{2, *}$ \\ 1 Graduate School of Education, Gachon University, 1342 Seongnam-daero, Sujung-gu, Seongnam-si 13120, \\ Gyeonggi-do, Korea; ongang@gachon.ac.kr \\ 2 Department of Applied Statistics, Gachon University, 1342 Seongnam-daero, Sujung-gu, Seongnam-si 13120, \\ Gyeonggi-do, Korea \\ * Correspondence: nhkim@gachon.ac.kr; Tel.: +82-31-750-5390
}

Citation: Paek, S.; Kim, N. Analysis of Worldwide Research Trends on the Impact of Artificial Intelligence in Education. Sustainability 2021, 13, 7941. https://doi.org/10.3390/ su13147941

Academic Editor: Kyong Joo Oh

Received: 18 June 2021

Accepted: 13 July 2021

Published: 16 July 2021

Publisher's Note: MDPI stays neutral with regard to jurisdictional claims in published maps and institutional affiliations.

Copyright: (C) 2021 by the authors. Licensee MDPI, Basel, Switzerland. This article is an open access article distributed under the terms and conditions of the Creative Commons Attribution (CC BY) license (https:/ / creativecommons.org/licenses/by/ $4.0 /)$.

\begin{abstract}
In today's world, artificial intelligence (AI) and human intelligence coexist, and no field is free from the impact of AI. At present, education cannot be discussed without mentioning AI, which has an omnidirectional impact on all its areas, including the purpose, content, method, and evaluation system. This study aimed to explore the future direction of education by examining the current impact and predicting future impacts of AI. It also examined research trends and collaboration status by country through network analysis, topic modeling and global research trends in AI in education (AIED), by applying the Latent Dirichlet Allocation algorithm. Over the past 20 years, the number of papers on AIED has steadily increased, with a dramatic rise since 2015. The research can be broadly classified into eight topics, including "changes in the content of teaching and learning." Using a linear regression model, three hot topics, two cold topics and trend changes for each research topic were identified. The study found that AIED research should be more thematically diversified and in-depth; this directly applies AI algorithms and technologies to education, which should be further promoted. This study provides a reference for exploring the direction of future AIED research.
\end{abstract}

Keywords: artificial intelligence; artificial intelligence in education (AIED); deep learning; machine learning; research trends; topic modeling; Latent Dirichlet Allocation (LDA); network analysis

\section{Introduction}

Today, we live in an artificial intelligence (AI) society, in which people can easily experience $\mathrm{AI}$ anytime and anywhere. AI has become commonplace and ubiquitous, ranging from AI speakers to high-performance robots. It has become a key driver of transformation in almost all areas, including personalized online education systems, medical services (health care, prescription/treatment), automobiles (autonomous vehicles, transportation services), manufacturing (process optimization, smart factory), finance (investment, trading, credit evaluation), media (content, advertisement), agriculture (weather data, farm management), energy (energy management), communication (communication resource distribution), and distribution (omnichannel platform) [1] (pp. 47-80).

Humanity has long been striving to create an automated and intelligent workforce that humans can freely utilize. The "automated and intelligent workforce" created by humans evolved into "AI." This means "the engineering and science of making intelligent machines," as proposed by McCarthy at the Dartmouth Conference in 1956 [2]. The Oxford English Dictionary defines AI as "computer systems able to perform tasks that normally require human intelligence, such as visual perception, speech recognition, decision-making, and translation between languages" [3].

However, the development of AI has not been smooth. When the concept of AI was first proposed in the 1950s, it entered the limelight due to widespread anticipation, but it twice faced the stagnation of an "AI Winter," due to a lack of effective implementation methodologies [4]. Artificial intelligence has made rapid progress since the beginning of 
the 21st century and is now entering an age of AI renaissance. In particular, in 2016, the Go match between nine-dan-ranked Sedol Lee and Deep Mind's AlphaGo ended in AlphaGo's victory, heralding the arrival of a fully-fledged AI era [4].

AI has three growth factors: algorithms, big data, and computing power. AI rapidly advanced as computing power grew, excellent algorithms emerged, and data accumulated due to the spread of smartphones and the development of networks in the 2000s [4]. The performance, penetration, growth, and impact of AI significantly improved as big data, cloud computing, and related computing and storage performance became available, due to a breakthrough in AI technology called "Machine Learning (ML)" and "Deep Learning (DL)" [1] (p. 21).

The rapid development of AI technology is universalizing the application and use of "AI in education (AIED)" [5-7]. AI has a fundamental and far-reaching impact on education. The problem-solving knowledge transfer type of education is being converted into a creative convergence type of education. The collective-type public education, based on the industrialization era, is being transformed into personalized education based on the AI era. The purpose, content and method of education are changing all at once. Furthermore, AI is changing the paradigm of education [8].

Currently, an in-depth exploration of education in the AI era is urgently needed. Thus, the impact of AI on education needs to be identified and the ways in which AI affects education needs to be closely examined. In particular, as the number of published AIED research papers increases, it is necessary and essential to systematically clarify and discuss related issues. There are several studies that explore the issues associated with the application of AI in the context of education [9-13]. However, these studies approach bibliometrics analysis from a partial perspective, such as higher education [9] and special education [10]. Thus, there is still a lack of systematic research to comprehensively grasp the research trends of AIED in the context of training as a whole.

In this context, it would be appropriate and meaningful to analyze AIED research topics and global trends. This study examined the impact of AI on education using the Latent Dirichlet Allocation (LDA) model. The topic modeling approach is a useful algorithm for mechanically identifying potential topics in unstructured documents such as papers, and it also provides a useful framework for understanding international research trends $[14,15]$. It provides meaningful implications for opening the future of AIED by analyzing the research trends of papers on AIED published in the last 20 years, since 2001. This study aimed to explore the future direction of education by examining the current impact and predicting future impacts of AI on education.

The remainder of this paper is organized as follows. Section 2 examines the theoretical background of this study, with AIED explored, and an overview of the LDA topic model as a methodological background is provided. Section 3 presents the research method and applies the analysis of networks between countries and LDA topic modeling to the subject data. Section 4 analyzes AI topics in education by deriving the research results. Section 5 discusses the research results. Section 6 presents the limitations of this study. Section 7 concludes the paper.

\section{Theoretical Background}

Our research is based on AIED and topic modeling. This section briefly overviews this theoretical background.

\subsection{AI and Education}

First of all, we consider artificial intelligence and education as the contextual background to this study. The study aims to examine the theoretical background by dividing it into three main areas, from the perspective of the understanding and use of AI as well as how it cultivates talent. The first is "education for understanding AI," which aims to develop the ability to understand and handle AI. The second is "education using AI," 
which applies AI to effective teaching and learning in each subject. The third is "AI expert training," which cultivates experts who develop AI and teachers who teach AI.

\subsubsection{Education for Understanding AI}

We are now in an era where it is not possible to discuss education without mentioning $\mathrm{AI}$, which has an omnidirectional effect on all its areas, including the purpose, content, educational methods, and evaluation systems [16]. Thus, countries around the world are including AI literacy education as a mandatory course to enhance the understanding of AI $[7,8]$. Artificial intelligence literacy education consists of methods for using AI devices and services, AI ethics, real-life AI convergence cases, and basic block coding. Education for understanding $\mathrm{AI}$ includes a reformed curriculum that reflects $\mathrm{AI}$, such as acquiring the principles of AI and convergence of courses $[7,8]$.

The major cases of education for understanding AI carried out by governments or the private sector around the world are as follows: "AI for ALL" in the United States (U.S.) emphasizes that AI education should target all citizens. It calls for AI education to solve social problems and to create and provide a free AI education platform [17]. The Association for the Advancement of AI in the U.S. presented AI education standards for K12 students $[18,19]$. Through the "AI in the UK" report, the United Kingdom suggests that knowledge and understanding of $\mathrm{AI}$ is essential for all children and that ethical judgment and the use of AI technologies should be integral parts of the curriculum [20]. Finland has developed a free online course for AI basic education by organizing a curriculum called "Elements of AI" [21]. Since 2019, China has been developing and applying an "AI experiment textbook," which is an AI textbook for those ranging from toddlers to university students [22]. Korea plans to strengthen "AI education" through the revision of the school curriculum in 2022 and educating students on the basic principles of AI, the use of $\mathrm{AI}$, and $\mathrm{AI}$ ethics [23].

\subsubsection{Education on the Use of AI}

The key to identifying the impact of AI on education lies in a system that can use AI for education, that is, artificial intelligence in education (AIED). Holmes, Bialik, and Fadel [5], among others, have generally divided AIED into the following three parts [16].

The first is the use of an intelligent tutoring system (ITS), which determines the optimal step-by-step learning path for a well-defined domain of "structured knowledge," such as mathematics or physics. ITS can be divided into domain models, pedagogical models, and learner models, according to the nature of the knowledge. The domain model addresses content knowledge for learning, the pedagogical model addresses pedagogical knowledge for teaching, and the learner model addresses the students' knowledge. ITS utilize these three models to develop a system, provide customized activities, collect learners' activity data, analyze the collected data, and update the model itself [5]. Representative AIEDs using ITS include MATHia at the Carnegie Mellon University [24].

The second is the use of a "Dialogue-based Tutoring System (DBTS)," which engages students in the dialog of learning by utilizing advanced natural language processing and natural language generation technology. Autotutor, developed by the University of Memphis, is an example of a DBTS using the principle of the Socratic dialog method [25]. That is, when a learner responds to a question or problem in writing or verbally, Autotutor recognizes the answer, determines the learner's level of understanding, and provides feedback to help the learner understand the answer by correcting misconceptions [26]. In other words, a DBTS can be said to be a precise addition of the collection and analysis functions of learner responses to an ITS.

The third is the use of an exploratory learning environment (ELE). Exploratory learning environments provide automated feedback to correct learners' erroneous learning outcomes by applying a constructive approach. That is, learners are encouraged to actively construct knowledge on their own by exploring and manipulating elements of the learning environment rather than following a set step-by-step sequence. Exploratory learning en- 
vironments are atypical and open learning environments, in which learners can explore as they wish [27,28]. Programs, such as "Fractions Lab" [29] and "Betty's Brain" [30], are representative examples.

\subsubsection{AI Expert Training Education}

With the explosive growth of AI technology, there is a shortage of talented people with the ability to continuously develop and research AI technology and those who can train them professionally. Countries around the world are adopting various policies to secure talent in the AI field, as they are in fierce competition [31,32]. Furthermore, there is a shortage of teachers who can teach AI curricula.

"AI expert training education" is broadly divided into a system that trains experts who develop AI and a system that cultivates teachers who will teach AI. AI model development requires knowledge of computer structures, programming languages, and various development tools, as well as knowledge about statistics, linear algebra, and differential equations. There is a limited number of talented people with this specialist knowledge. Countries around the world have established AI departments and are accelerating the training of AI experts in master's and doctoral programs [31,32]. In addition, they are expanding interest in training teachers who can teach AI from an educational perspective, such as AI literacy for K-12 courses [31,32].

For example, South Korea announced the "National Strategy of AI" in 2019 and a plan to foster high-level human resources at the master's and doctoral levels, such as creating or expanding AI-related departments in the undergraduate programs of universities and establishing AI graduate schools to foster AI experts [33]. Moreover, to strengthen the AI capabilities of teachers, it stated that it will cultivate 10,000 incumbent teachers as AI instructors by providing customized AI training for each school level and acquiring the latest technology trends by 2021. Furthermore, it stated that retraining to strengthen AI convergence education competency will be carried out for 5000 incumbent instructors of 38 graduate schools of education by 2025 [33].

\subsection{Topic Modeling}

To derive the latent topics of AIED research, we used topic modeling. Topic modeling is a statistical model that automatically finds natural groups of topics in large documents. Other commonly used methods for finding research topics include manual allocation or network clustering $[34,35]$. These methods are not suitable for large documents and can be limited in that only one topic exists in one document. In topic models, it is assumed that several topics are mixed in each document and that each topic has a word distribution. These assumptions of the topic model are suitable for finding research topics from articles because research papers usually do not have only one topic but include several topics at the same time. Topic models provide a theoretical background that can help understand the document creation mechanism, and documents can be automatically organized and summarized. Topic models have been used to analyze research trends in various research fields, such as education [36,37], statistics [38], machine learning [39], biochemistry [40], and manufacturing [41].

Latent Dirichlet Allocation is a representative algorithm for topic modeling [42]. Latent Dirichlet Allocation assumes that each word in the document is generated as follows: In Corpus $C$ with $D$ documents, one document $d$ consists of $N_{d}$ words. Document $d$ has a distribution of $K$ topics $\theta_{d}$, and when creating the nth word $w_{d, n}$, one topic $z_{d, n}$ $\left(z_{d, n} \in\{1, \ldots, K\}\right)$ from the $K$ topics is selected according to the distribution $\theta_{d}$, and the word $w_{d, n}$ is generated according to the word distribution $\beta_{z_{d, n}}$ of the topic $z_{d, n}$.

Here, the topic distribution $\theta_{d}$ of document $d$ and word distribution $\beta_{k}$ for topic $k$ follow the Dirichlet distribution, and $\alpha$ and $\eta$ are the parameters of the Dirichlet prior, respectively.

In the document, only the generated words $\mathrm{w}_{\mathrm{d}, \mathrm{n}}$ are observed and the rest become latent variables $\left(\theta_{d}, \beta_{k}, z_{d, n}\right)$ and hyperparameters $(\alpha, \eta)$. By maximizing the joint probability 
of the words in a document in the corpus, the latent variables $\theta_{d}, \beta_{k}$ can be obtained. From the estimated $\theta_{d}$, we can determine the latent topics of each document.

\section{Research Framework}

In this section, we explain the methods and procedure for trend analysis. As shown in Figure 1, the procedure comprises three steps: (1) data collection and text preprocessing; (2) frequency and collaboration network analysis; (3) topic analysis.
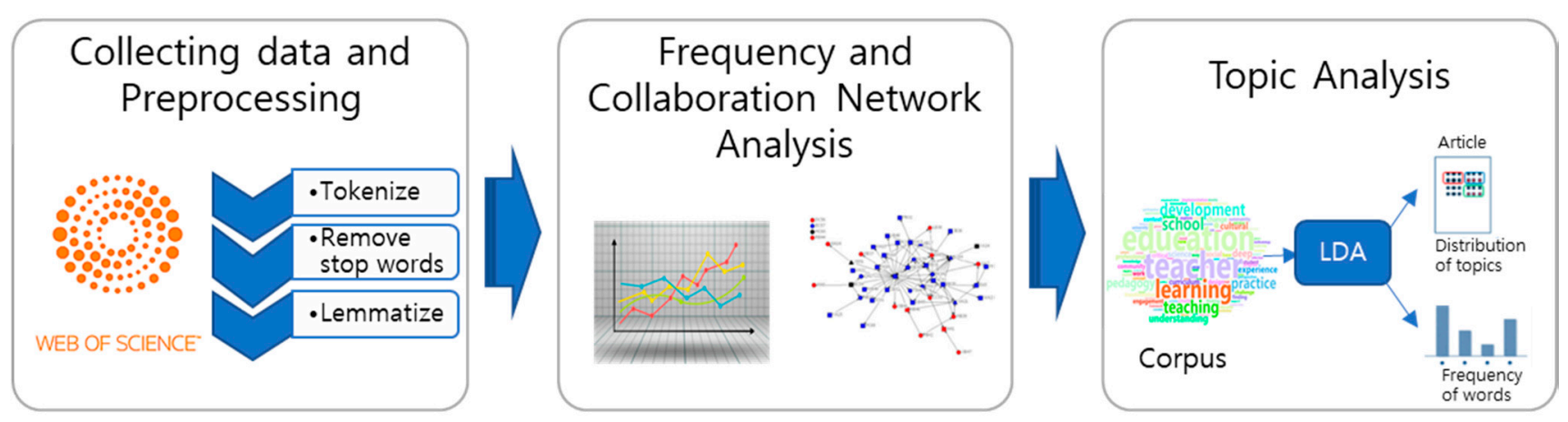

Figure 1. Research Framework.

\subsection{Data Collection and Text Preprocessing}

Data were collected and preprocessed to investigate AIED-related research trends. Bibliographical information was retrieved from the Web of Science database, provided by Clarivate Analytics. Web of Science provides comprehensive bibliographic data for various fields of study. A total of 5043 published articles from 2001 to 2021 were retrieved on 21 May 2021, through a topic search using the terms "artificial intelligence," "AI," "machine learning," or "deep learning" from the Web of Science core collection. We set the search queries by referring to the previous studies $[6,39,43]$. To be specific to the field of education, we limited the Web of Science categories to the following two categories: "Education Scientific Disciplines" or "Education Educational Research." The database includes SCI-EXPANDED, SSCI, A\&HCI, and ESCI. Since abstracts are required for topic analysis, 5035 papers remained, excluding papers without abstracts.

For basic frequency analysis and collaboration network analysis, the publication year and authors' addresses were used. If there were multiple authors, the collaboration relationship was investigated by checking the country of affiliation of all authors.

To conduct LDA, a dictionary and corpus consisting of the title, keywords, and abstract of the paper were required. The language used in the analysis was English. To create a dictionary and corpus, preprocessing was performed on the collected texts. First, Python NLTK's regular-expression tokenizer was used for tokenization [44]. Then, the numbers, punctuations, and stop words were removed. In addition, general words used in research articles, such as "paper," "study," "article," "research," and "result," as well as words with a word length of two or less and rare words with a frequency of less than five, were removed. Lemmatization was used to reduce the size of the vocabulary set. Lemmatization and stemming are two representative methods used to reduce the size of the vocabulary set, but lemmatization creates words that are easier to interpret than stemming; thus, lemmatization is preferable in LDA, where semantic interpretation is important. In addition, some studies have shown that stemming has no significant effect on LDA $[45,46]$. For lemmatization, Python's spaCy library was used [47]. A dictionary was created for the lemmatization data and the documents were vectorized with bag-of-words to calculate the frequency of words in each document. A dictionary was created through Gensim's corpora.dictionary and the corpus was created through the integer encoding of dictionary.doc2bow. 


\subsection{Frequency and Collaboration Network Analysis}

Firstly, a publication frequency analysis and collaboration network analysis were performed on the collected articles. The publication trends of papers by year and research collaborations between countries were analyzed. We analyzed international research cooperation through a network analysis. The network consists of nodes and edges. A collaboration network is constructed with each country as a node and the number of collaborative papers between countries as the edge weight. Through a collaboration network, the degree centrality for each country is obtained as the sum of the weights of all the edges connected to a node. It can be interpreted that the higher the degree value, the more active the collaboration [48].

\subsection{Topic Analysis}

The LDA model was applied to the text data that had previously been preprocessed. Latent Dirichlet Allocation analysis was conducted using the Genism LDA model. To find the optimal hyperparameter values and the number of topics, the settings shown in Table 1 were used by referring to related papers [39,49].

Table 1. LDA experiment settings.

\begin{tabular}{cc}
\hline Component & Candidates \\
\hline num_topics $(K)$ & $5-30$ \\
alpha & $1 / \operatorname{sqrt}(K), 50 / K$, “auto" \\
eta & $0.01,0.1$, "auto" \\
passes & $10,20,30-35$ \\
iterations & $1000,3000,5000,10,000$ \\
\hline
\end{tabular}

To determine the number of topics $(K)$, we used from $K=5$ to $K$. $=30$. The optimal number of topics was selected by comparing the coherence scores. Perplexity is widely used in the evaluation of language models. However, recent studies have shown that perplexity and human judgment are often uncorrelated [50]. The coherence score is more relevant to human judgment, so we used coherence scores as a metric [51]. The higher the coherence value, the better the performance. The results showed that eight topics consistently scored high in coherence. The number of topics was then set to eight and hyperparameters were adjusted to create the LDA model. The selected hyperparameter value was alpha $=$ "auto," eta $=$ "auto," passes $=35$, iterations $=10,000$, and num_topics $=$ 8. For passes, the performance at 30 was better than at 10 and 20, and performance from 30 to 35 tended to improve steadily, though there was no significant difference; thus, 35 was used for passes. The value of coherence was high when "auto" was used for alpha and eta, which were automatically obtained from the corpus.

\section{Results}

\subsection{Frequency and Collaboration Network Analysis}

The number of articles published annually is increasing exponentially. Until 2006, only a small number of papers related to AI and education were published. After that, it increased until 2008, but was stuck in low growth and even slightly decreased in 2014. However, Figure 2a shows that it sharply increased again after 2014. In particular, the number of papers on AI and education has significantly increased in recent years, and papers published after 2018 account for 37\% (1872 papers) of the total. The so-called "Third AI Boom," which has developed since the 2010s, seems to have been reflected upon [4,5,16]. In particular, the rapid development of AI algorithms, such as machine learning and deep learning, the improvement of computing power, and the accumulation of big data, have become catalysts. Figure $2 \mathrm{~b}$. shows the relative ratio of the top six countries in terms of the number of papers. The blue line with dots on the right auxiliary axis shows the trend for the sum of these six countries. The United States accounted for the largest share, but it is slowly declining, while China's recent growth has been steep. Australia and England have 
also traditionally accounted for a large proportion, but they show a gradual decline. This could be interpreted as AIED research being conducted in increasingly diverse countries. In fact, the number of paper-publishing countries increased from four countries in 2001 to 32 countries in 2011, increasing to 98 countries by 2020 .

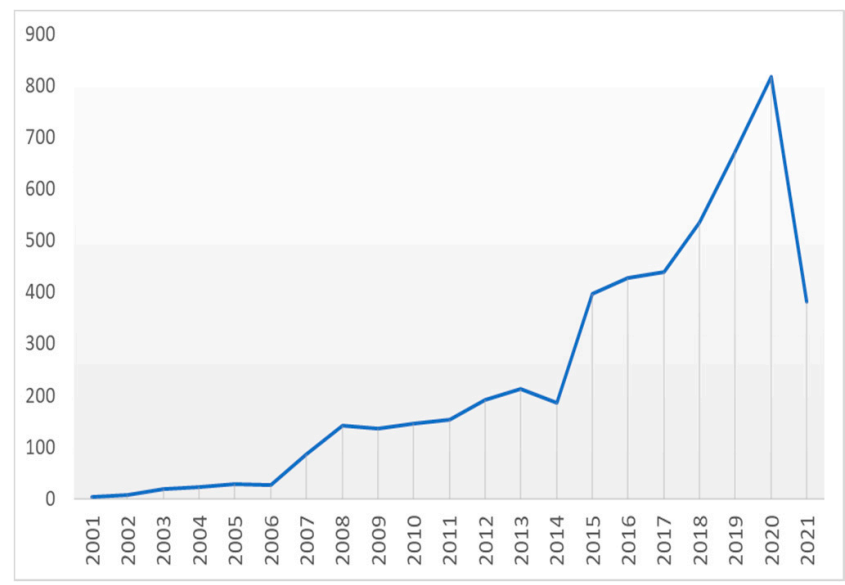

(a)

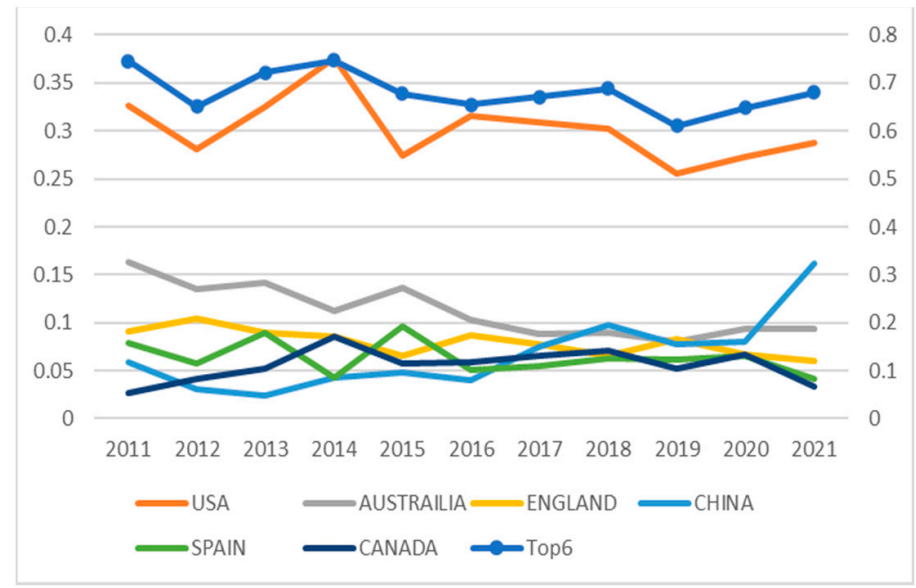

(b)

Figure 2. (a) Number of publications by year; (b) Relative ratio of the number of papers by country (top six countries).

To examine the cooperative relationship between countries, 5031 papers were analyzed by country, excluding papers without author information. Figure 3 indicates the frequency of country-level collaboration for the top 40 countries, in terms of the total number of papers. In the graph, the $y$-axis is the number of collaborated papers, the $x$-axis is the collaboration ratio, and the size of the bubble is proportional to the number of papers. Among the 5031 papers, $15.88 \%$ (799 papers) were the result of international collaboration. The United States published the most papers (276 papers), but the collaboration rate was low $(18.83 \%)$ compared to the other top countries. For the top 40 countries, the average collaboration ratio was $34 \%$. By continent, countries in Europe have a high collaboration ratio, but there are two exceptions: Ukraine (12\%) and Spain (21.77\%). Among Asian countries, South Korea showed the highest collaboration ratio (57.45\%). In Canada, both the number of collaborative papers (113 papers) and the collaboration ratio (40.36\%) were high.

Figure 4 shows the collaboration networks of the top 30 countries. The size of the node is proportional to the degree centrality, the thickness of the edge is proportional to the number of collaborated papers between two countries, and the dashed line indicates that there is only one collaborative paper. Various collaborative relationships between European countries are observed, and some Asian countries are observed to have strong collaborative relations with the United States. Australia and England are also actively cooperating with countries on various continents. The strongest relationship exists between the United States and Canada. Next, strong connections are found between the United States and China, the United States and Australia, Australia and the United Kingdom, and the United States and Israel. The research topics which exist between them are identified in Section 4.2.1, once they are derived through LDA. 


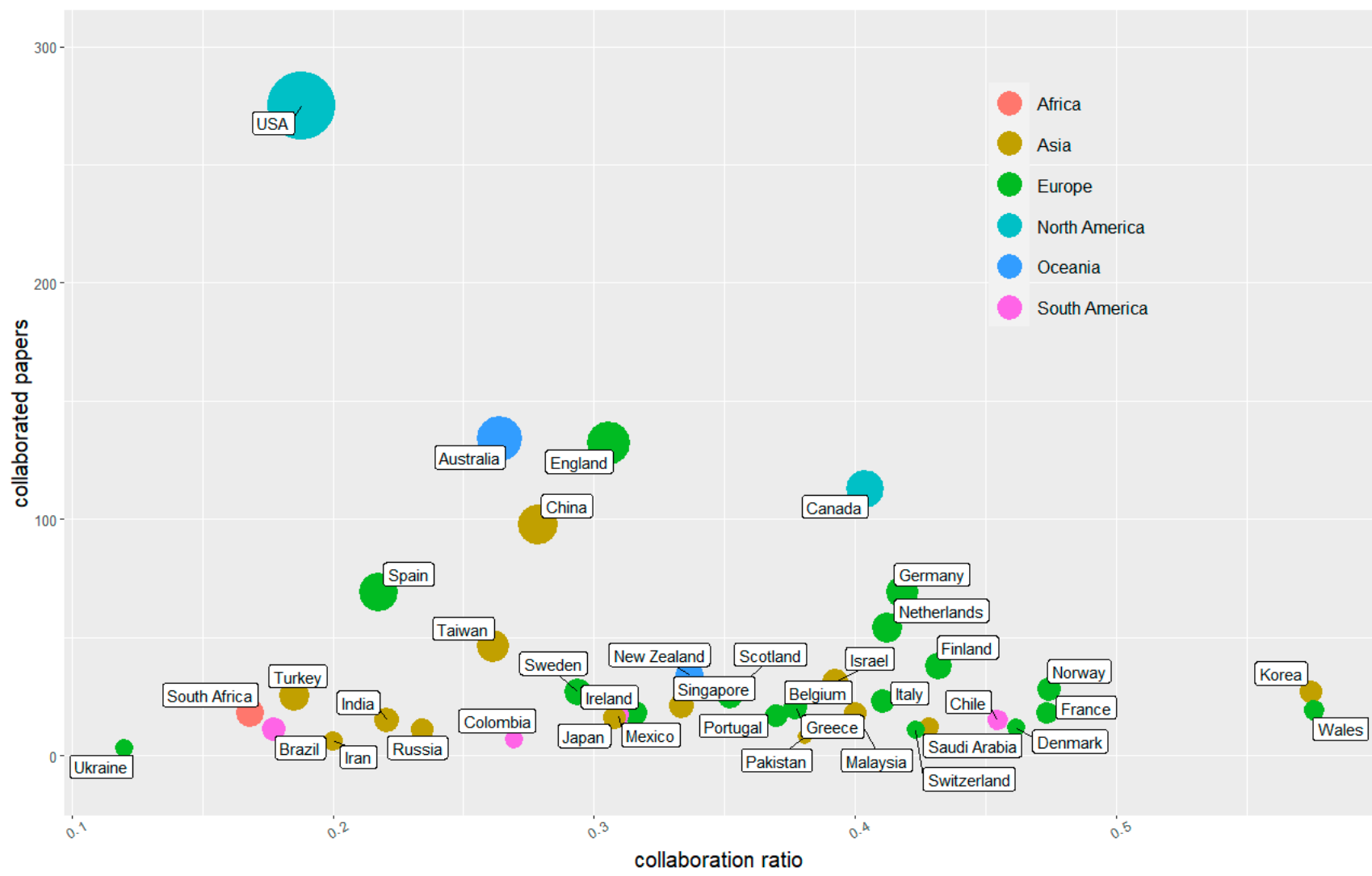

Figure 3. Country-level collaboration for the top 40 countries.

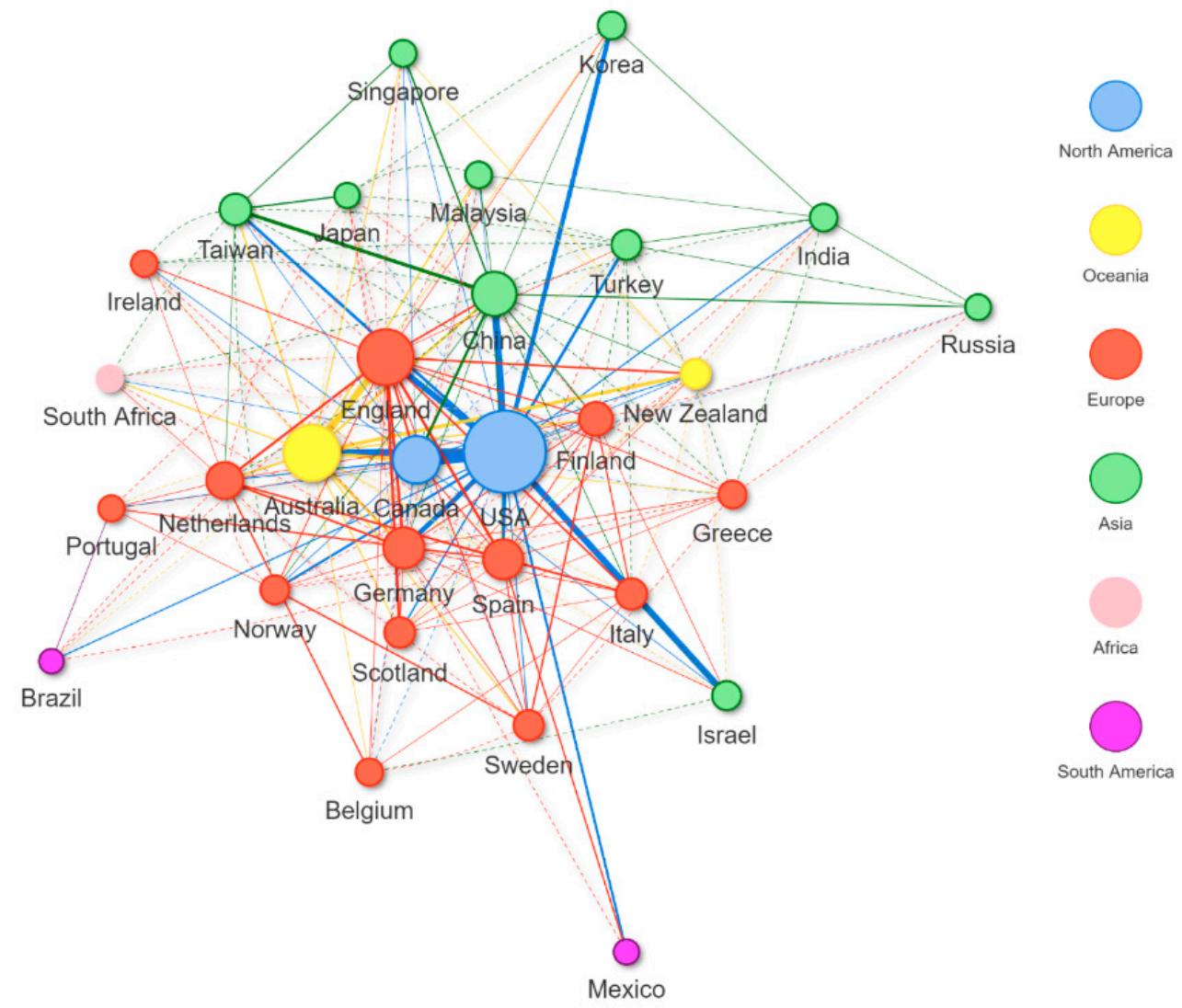

Figure 4. Top 30 countries collaboration network. 
Table 2 shows the top 20 countries in terms of degree centrality. Total (Rank), CP, CR, and CC denote the number of total papers with rank, the number of collaborated papers, the collaboration ratio, and the number of collaboration countries, respectively. The United States plays a central role in collaboration. An interesting observation is that Canada plays a more central role than its total papers. Although its total publication is ranked sixth, it is the fourth most central country in the collaboration network. Most Asian countries, including China, have a lower centrality ranking than total publications, whereas European countries have a higher centrality ranking than total publications.

Korea and Spain are the exceptions: Korea has a higher centrality ranking (19th) than the total publication ranking (27th), while Spain has a lower centrality ranking (7th) than the total publication ranking (5th).

Table 2. Top 20 countries in terms of degree centrality.

\begin{tabular}{lccccccc}
\hline Rank & Country & Continent & $\begin{array}{c}\text { Total } \\
\text { (Rank) }\end{array}$ & CP & CR & CC & Degree \\
\hline 1 & USA & North America & $1466(1)$ & 276 & $18.83 \%$ & 59 & 334 \\
2 & Australia & Oceania & $510(2)$ & 134 & $26.27 \%$ & 46 & 189 \\
3 & England & Europe & $433(3)$ & 132 & $30.48 \%$ & 52 & 188 \\
4 & Canada & North America & $280(6)$ & 113 & $40.36 \%$ & 34 & 141 \\
5 & China & Asia & $353(4)$ & 98 & $27.76 \%$ & 37 & 122 \\
6 & Germany & Europe & $166(8)$ & 69 & $41.57 \%$ & 32 & 105 \\
7 & Spain & Europe & $317(5)$ & 69 & $21.77 \%$ & 35 & 99 \\
8 & Netherlands & Europe & $131(10)$ & 54 & $41.22 \%$ & 29 & 81 \\
9 & Finland & Europe & $88(14)$ & 38 & $43.18 \%$ & 29 & 64 \\
10 & Taiwan & Asia & $176(7)$ & 46 & $26.14 \%$ & 15 & 52 \\
11 & Italy & Europe & $56(22)$ & 23 & $41.07 \%$ & 21 & 50 \\
12 & Scotland & Europe & $71(16)$ & 25 & $35.21 \%$ & 19 & 47 \\
13 & Sweden & Europe & $92(13)$ & 27 & $29.35 \%$ & 18 & 45 \\
14 & Turkey & Asia & $136(9)$ & 25 & $18.38 \%$ & 28 & 43 \\
15 & New Zealand & Oceania & $102(12)$ & 34 & $33.33 \%$ & 14 & 42 \\
16 & Israel & Asia & $79(15)$ & 31 & $39.24 \%$ & 10 & 38 \\
17 & Norway & Europe & $59(20)$ & 28 & $47.46 \%$ & 16 & 37 \\
18 & Greece & Europe & $53(24)$ & 20 & $37.74 \%$ & 21 & 31 \\
19 & Korea & Asia & $47(27)$ & 27 & $57.45 \%$ & 11 & 31 \\
20 & India & Asia & $68(17)$ & 15 & $22.06 \%$ & 19 & 30 \\
\hline
\end{tabular}

\subsection{Topic Discovery and Research Trend Analysis}

Before topic modeling, a word network was constructed by creating association rules between frequently appearing words through association analysis on preprocessed text data. Association analysis mines frequent itemsets, association rules, or association hyperedges using the Apriori algorithm. The Apriori algorithm employs level-wise search for frequent itemsets [52-54].

Figure 5 shows a word co-occurrence network created using words present in the corpus. Words such as "learning," "deep," "student," and "education," occupy the center of the network, as they are connected with many other words. 


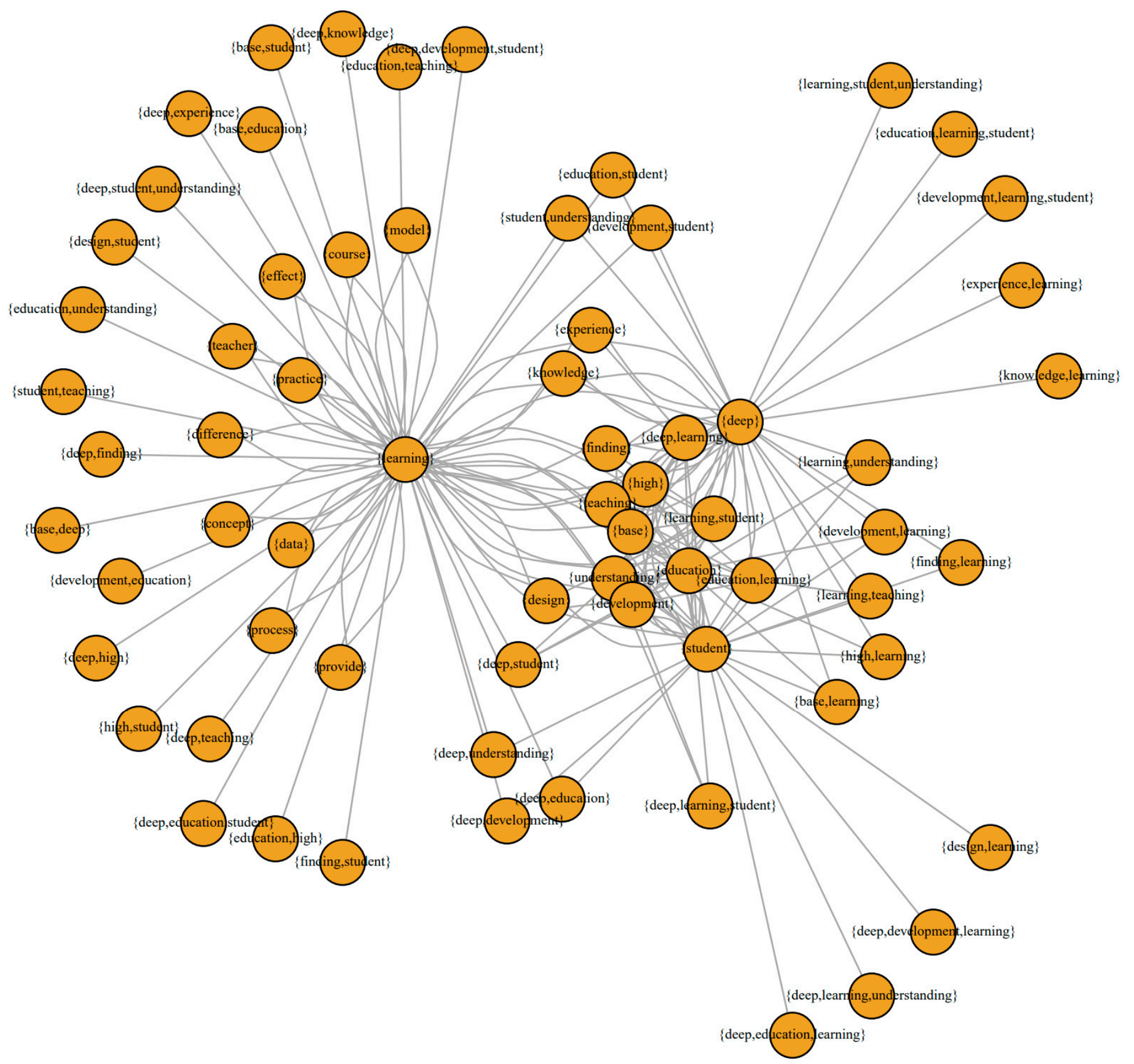

Figure 5. Word network.

\subsubsection{Topic Modeling Analysis}

The number of topics was set to eight by reviewing the coherence score and using the LDA algorithm. Each topic was rearranged in descending order according to proportion, and the number of topics was assigned. Table 3 shows the eight topics derived from LDA topic modeling, together with the assigned topic names, the list of words included in the order of probability of appearance, and the proportion of each topic. The LDA algorithm did not automatically generate labels for the topics. By considering frequent words for each topic first, and then extracting five articles with high topic weight and high citation frequency for each topic, the title and abstract were reviewed and assigned. 
Table 3. Topics and frequent words.

\begin{tabular}{|c|c|c|c|}
\hline No. & Topic Name & Frequent Words & Proportion \\
\hline Topic 1 & $\begin{array}{l}\text { changes in the } \\
\text { content of teaching } \\
\text { and learning }\end{array}$ & $\begin{array}{l}\text { teacher, education, learning, teaching, } \\
\text { school, development, practice, } \\
\text { pedagogy, deep, understanding, } \\
\text { cultural, experience, science, curriculum, } \\
\text { social }\end{array}$ & $21.40 \%$ \\
\hline Topic 2 & $\begin{array}{l}\text { feedback on } \\
\text { assessment and } \\
\text { evaluation }\end{array}$ & $\begin{array}{l}\text { student, learning, assessment, course, } \\
\text { base, teaching, group, test, deep, } \\
\text { undergraduate, design, feedback, } \\
\text { activity, evaluation, chemistry }\end{array}$ & $18.00 \%$ \\
\hline Topic 3 & $\begin{array}{l}\text { enhancing } \\
\text { interaction in online } \\
\text { learning }\end{array}$ & $\begin{array}{c}\text { learning, student, online, interaction, } \\
\text { design, technology, collaboration, } \\
\text { learner, engagement, activity, } \\
\text { environment, base, course, game, deep }\end{array}$ & $14.50 \%$ \\
\hline Topic 4 & $\begin{array}{l}\text { learning strategies } \\
\text { and academic } \\
\text { achievement }\end{array}$ & $\begin{array}{l}\text { learning, student, deep, high, self, } \\
\text { strategy, academic, education, } \\
\text { motivation, achievement, factor, } \\
\text { perception, model, science, university }\end{array}$ & $13.90 \%$ \\
\hline Topic 5 & $\begin{array}{l}\text { language learning } \\
\text { and literacy }\end{array}$ & $\begin{array}{l}\text { language, knowledge, concept, English, } \\
\text { writing, instruction, student, science, } \\
\text { reading, mathematics, learner, learning, } \\
\text { teacher, understanding, process }\end{array}$ & $9.90 \%$ \\
\hline Topic 6 & AI-driven edu-tech & $\begin{array}{l}\text { intelligence, artificial, education, system, } \\
\text { technology, teaching, base, machine, } \\
\text { development, computer, design, } \\
\text { computation, learning, data, application }\end{array}$ & $9.90 \%$ \\
\hline Topic 7 & $\begin{array}{l}\text { learning experience } \\
\text { and medical } \\
\text { education }\end{array}$ & $\begin{array}{l}\text { reflection, student, medical, experience, } \\
\text { skill, education, health, professional, } \\
\text { clinical, development, training, program, } \\
\text { learning, practice, participant }\end{array}$ & $8.60 \%$ \\
\hline Topic 8 & $\begin{array}{l}\text { machine learning } \\
\text { algorithm }\end{array}$ & $\begin{array}{l}\text { machine, data, model, predict, learning, } \\
\text { performance, classification, algorithm, } \\
\text { network, analyze, automate, accuracy, } \\
\text { feature, neural, image }\end{array}$ & $3.80 \%$ \\
\hline
\end{tabular}

Keywords, such as "teacher," "education," "learning," "teaching," "school," "development," "practice," "pedagogy," "deep," and "understanding," frequently appeared in Topic 1, as the general and universal topics covered in the traditional education field were addressed. Changes in educational content were explored while pursuing "deep understanding" and "deeper learning" using AIED. The topic was named "changes in the content of teaching and learning." There are papers such as [55-57] that show the features of this topic.

In Topic 2, keywords related to diagnosis and evaluation, which are traditionally addressed in the education field, such as "student," "assessment," "course," "base," "group," "test," "design," "feedback," "activity," and "evaluation," appeared frequently [58,59]. AIED was no different. The topic was named "feedback on assessment and evaluation." In education, the task of diagnosing and evaluating students is a major field that cannot be omitted. By using AI, effective methods of assessment and feedback will be developed.

Topic 3 was about online learning, such as distance learning. It was named "enhancing interaction in online learning" by especially considering keywords including "learning," "student," "online," "interaction," "design," "technology," "collaboration," "engagement," "activity," and "environment." In particular, the novel coronavirus disease 2019 (COVID-19) pandemic in 2019 heightened the power of non-face-to-face distance education. In turn, research on online learning based on AI has increased [60,61]. 
Keywords appearing in Topic 4, including "learning," "student," "deep," "high," "self," "strategy," "academic," "education," "motivation," "achievement," "factor," and "perception," are related to students' learning strategies and academic achievement, such as motivation. It was named "learning strategies and academic achievement." A student's academic achievement is affected by various learning strategies. In particular, learning motivation, such as self-esteem and self-awareness, is a traditional area that has been explored in the field of education for a long time. Therefore, there is a need for continuous exploration of AIED. There are papers such as $[62,63]$ that exhibit the features of this topic. Keywords that often appeared in Topic 5 are "language," "knowledge," "concept," "English," "writing," "instruction," "student," "science," "reading," and "mathematics." It was named "language learning and literacy" in consideration of the topic words for language learning, such as English and Chinese, and literacy education, such as mathematics and science. The use of AI in language learning and literacy education has been increasing. This topic is the field of education where machine learning algorithms, such as speech recognition, text recognition, and neural network machine translation technology, are most actively applied. There are papers such as $[64,65]$ that exhibit the features of this topic.

In Topic 6, keywords such as "intelligence," "artificial," "technology," "machine," "computer," "design," "computation," "learning," "data," and "application," which are mainly covered in AIED, appeared. The topic was named "AI-driven edu-tech." Attempts to double the educational effect by integrating technology into education, such as information technology, have already been made for a long time. Today, the integration of education and technology based on AI can been observed. This topic represents the technological applications of AIED [66,67].

As shown in Topic 7, there are many keywords related to learning experience and the medical field, including "reflection," "medical," "experience," "skill," "education," "health," "professional," "clinical," "training," "program," "practice," and "participant." The topic was named "learning experience and medical education." The medical field, which uses AI not only for student education, but also for patient diagnosis and treatment, is leading the way in the use of AIED, which, in medicine, will continue to be studied in the future $[68,69]$.

Topic 8 covers the core content of AI. Thus, words such as "machine," "data," "model," "predict," "learning," "performance," "classification," "algorithm," "network," "analyze," "automate," "accuracy," "feature," "neural," and "image" appeared frequently. The topic was naturally named "machine learning algorithm." It is a research topic that moves beyond simply using AI services for education and directly applies AI algorithms and technologies to education. This topic is likely to expand on the core topic of AIED. There are papers such as $[70,71]$ that exhibit the features of this topic.

By linking the topics derived from LDA to the previous network analysis, we can see what topics are being studied between countries. There was a high proportion of topics 1 , 2 and 7 between USA-Canada. Topics 3 and 5 were actively studied in USA-China, topics 1 and 5 in USA-Australia, topic 3 in Australia-England, and topics 1 and 7 in USA-Israel.

\subsubsection{Word Cloud Analysis}

Word cloud analysis enables an effective delivery of meaning by visualizing the results of topic modeling at a glance. Figure 6 presents the word cloud by topic. The higher the frequency, the larger the font size.

The word cloud analysis easily verified that keywords, including "teacher," "student," "education," "learning," "assessment," "online," "interaction," "language," "knowledge," "intelligence," "artificial," "reflection," "medical," "experience," "machine," "data," "model," and "predict," frequently appeared by topic. 


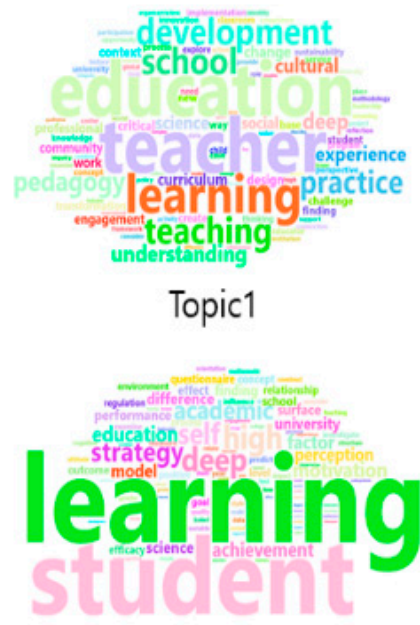

Topic4

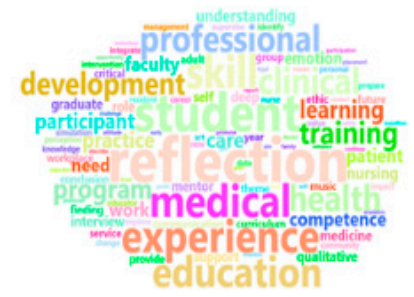

Topic7

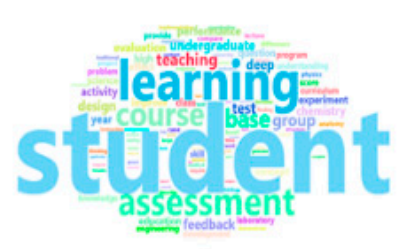

Topic2

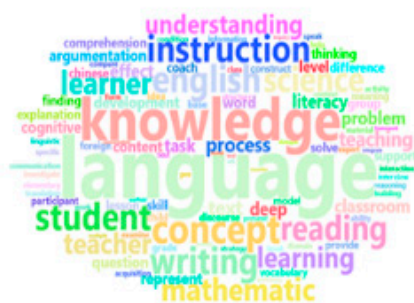

Topic5

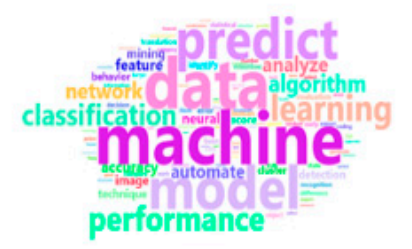

Topic8

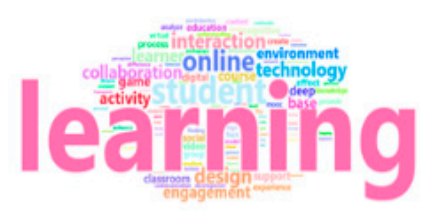

Topic3

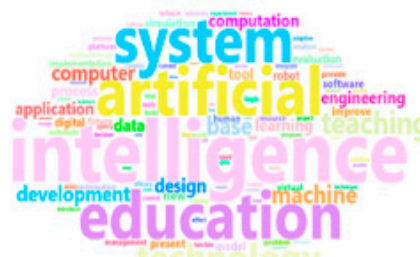

Topic6

Figure 6. Word cloud by topic.

\subsubsection{Time Series Regression}

How research topics have changed over the past 20 years, since 2001, was examined. Firstly, changes in the proportion of topics by year were explored. According to Figure 7, the proportion of Topic 3 began to increase in 2010, followed by Topic 6 and Topic 8 .

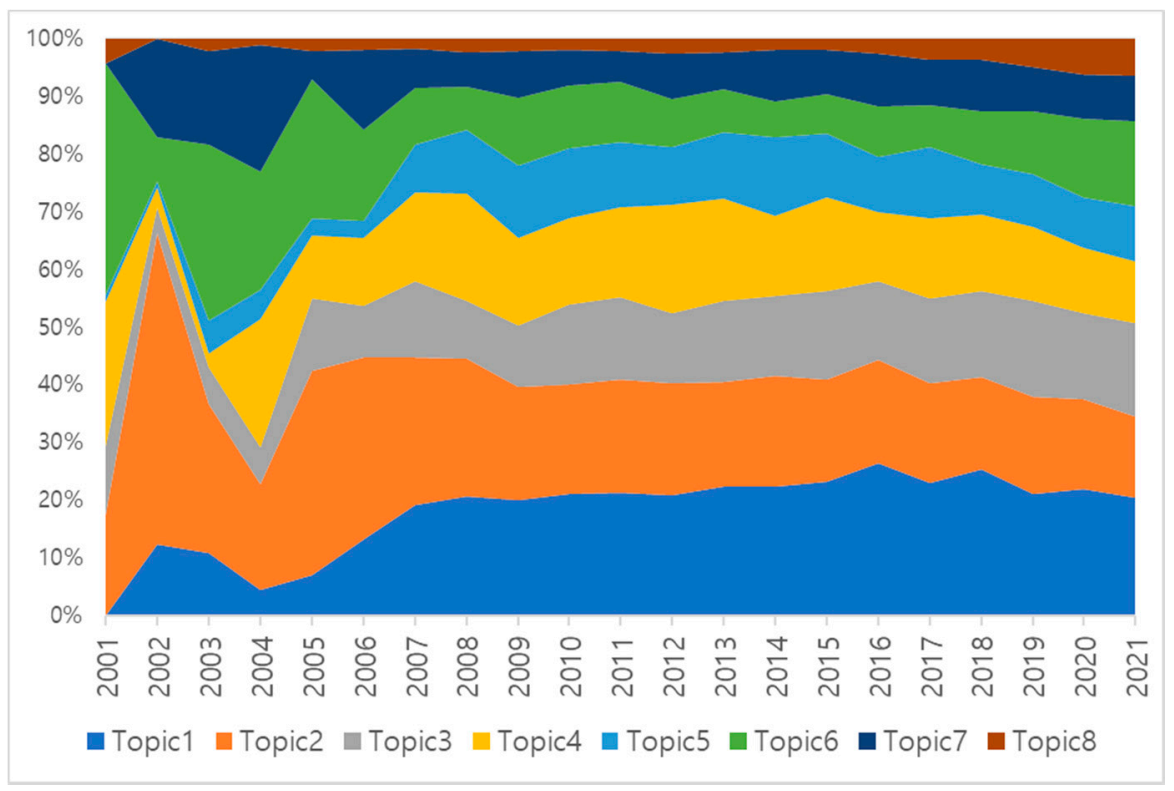

Figure 7. Topic proportion by year.

In addition, the trend of changes by year of the topic was identified. To investigate whether each topic is rising or falling, we employed linear regression to identify hot and 
cold topics [72]. A linear regression model was fitted using the topic weight for each year from 2001 to 2021 as the response variable and the year index as the input variable. Topics were classified as hot and cold topics according to their sign of slope and statistical significance $(\alpha=0.05)$. As a result, three hot topics and two cold topics were derived, as shown in Table 4 . Figure 8 shows the topic proportion by year of hot and cold topics.

Table 4. Hot/cold topics based on the linear regression.

\begin{tabular}{ccccc}
\hline Topic & Coefficient & Std. Error & $p$-Value & Hot/Cold \\
\hline Topic1 & 0.000180 & 0.001851 & 0.924513 & \\
Topic2 & -0.004858 & 0.000626 & 0.000028 & Cold \\
Topic3 & 0.002561 & 0.000815 & 0.011861 & Hot \\
Topic4 & -0.006470 & 0.001399 & 0.001243 & Cold \\
Topic5 & -0.002743 & 0.001308 & 0.065346 & \\
Topic6 & 0.005417 & 0.002094 & 0.029347 & Hot \\
Topic7 & 0.001445 & 0.001017 & 0.189169 & \\
Topic8 & 0.004469 & 0.000794 & 0.000324 & Hot \\
\hline
\end{tabular}

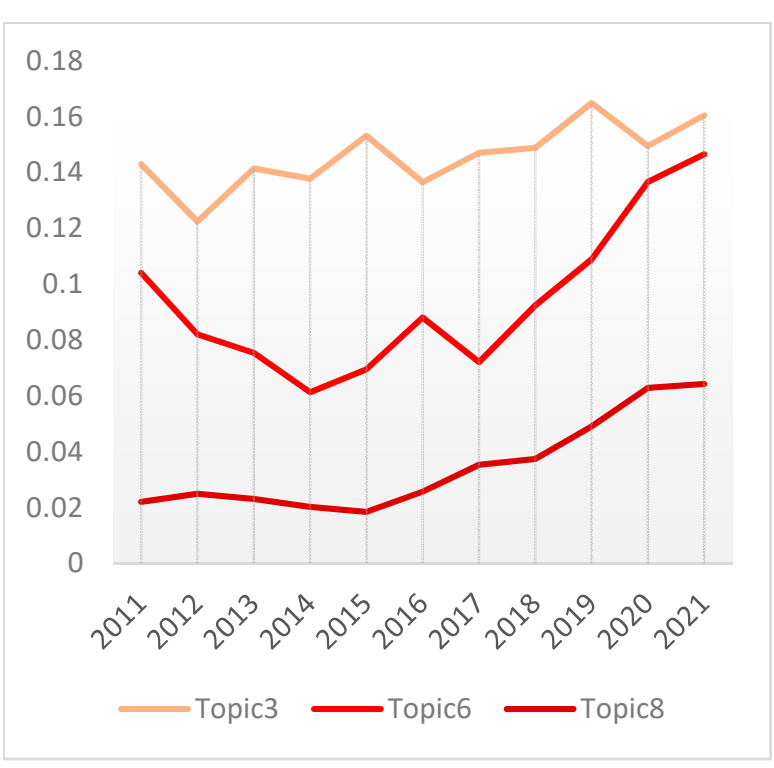

(a)

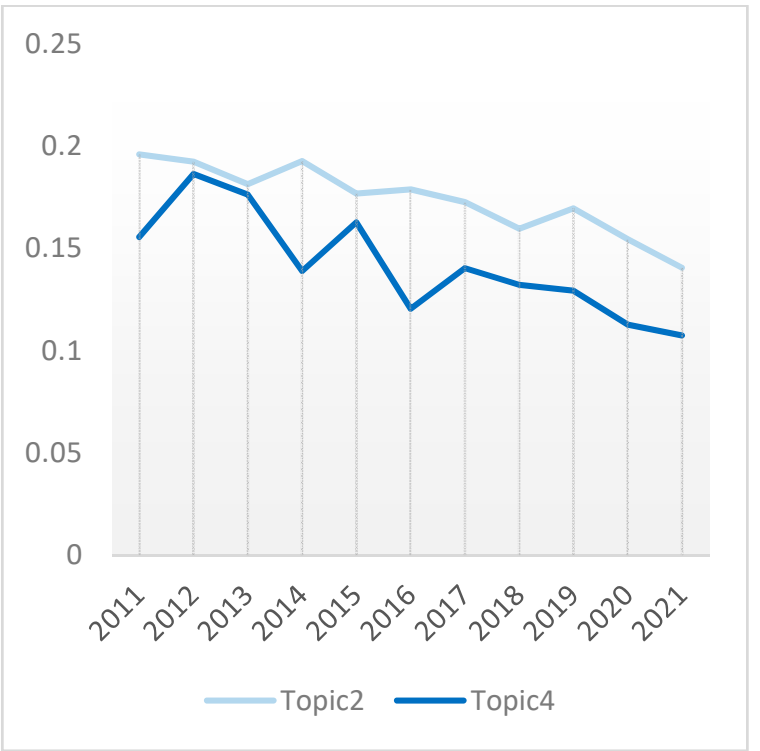

(b)

Figure 8. Topic proportion by year (a) Hot topic; (b) Cold topic.

Among the articles on Topic 3, [60], published in 2010, analyzed online learning, which was cited 250 times. Furthermore, [73], related to Topic 3 and published in 2015, also shows a high number of quotes, cited 274 times. According to these articles, the widespread adaption of online learning has caused many researchers to analyze the impact of the internet and web-based learning on education [60,73]. Other studies related to online learning using MOOC and SNS have been conducted [61,74-77].

With the development of AI technology for online lectures, research related to Topic 6 has increased $[66,67,78,79]$. In addition, as online lectures increased, students' activities were automatically recorded, resulting in data accumulation. As the data grows, the proportion of Topic8, which tries to evaluate students' achievement with the machine learning algorithm, appears to have increased [70,71,80,81]. In particular, [75] is derived from only three hot topics from LDA.

Hot topics are studied the most by the United States (332 papers), followed by China (188 papers), Spain (127 papers), England (97 papers) and Australia (95 papers), in terms of the number of publications. Especially in China, $53.26 \%$ of all articles deal with hot topics. 


\subsubsection{Topic Network Analysis}

As the LDA model allows multiple topics to appear in one document at the same time, co-occurrence between topics can be obtained. Using this method, a topic network was created. The network was constructed using topics as nodes and the frequency of co-occurrence between topics as weights of edges. Whether a specific topic appeared in the article was based on having a topic proportion exceeding 0.26 in consideration of the distribution of topic proportion values, and only edges with a co-occurrence frequency of more than 45 were used when configuring the network.

Figure 9 shows a topic network and its corresponding Sankey diagram, derived from the topic network. In Figure 9a, the red circle represents hot topics, and the blue circle represents cold topics. The size of the node is proportional to the topic proportion and the thickness of the edge is proportional to the number of the co-occurrence between two topics. The dashed line indicates that the co-occurrence number is less than 95 (the first quartile of edge weight values). Topic 1 appears evenly with other topics but does not appear simultaneously with Topic 8 , and Topic 8 appears simultaneously with Topic 3 only.

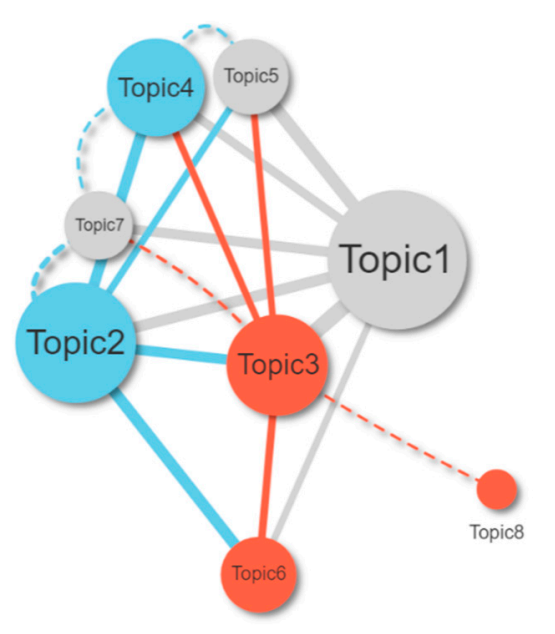

(a)

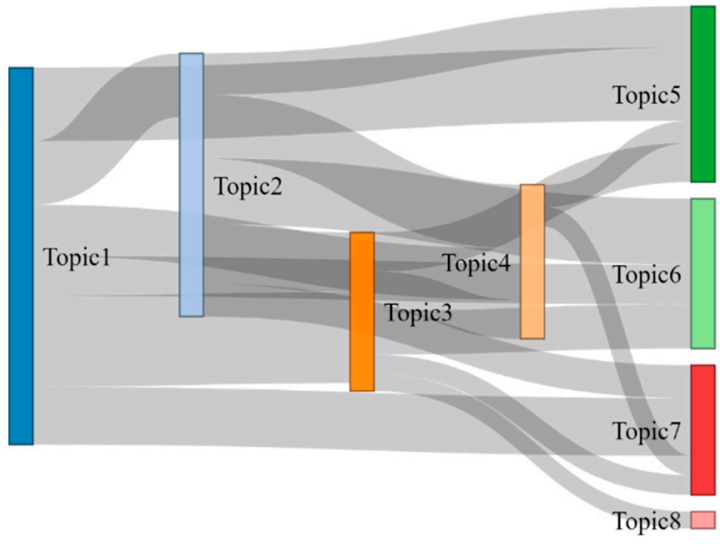

(b)

Figure 9. (a) Topic network (b) Sankey diagram of the topics.

\section{Discussions}

No field is immune from an AI shock. The field of education, which drives human social life by developing intelligence and utilizing intelligence, is directly affected by AI. This is because the educational effect can be multiplied by using AI in teaching and learning processes. Currently, AIED has become a constant rather than a variable. Based on the results confirmed in this study, the future direction of education is explored, while summarizing the impact of $\mathrm{AI}$ on education.

Firstly, research on AIED is increasing in quantity, but more research is still needed [5]. As you can see in Figure 2a, papers on AIED have been increasing since 2001. Research papers have been increasing exponentially since 2015, as papers published after 2019 accounted for 37\% (1872) of the total. This indicates that AIED has been an active research field since 2015. Education is a broad field that has economic, social, and cultural impacts. Various studies that redesign the paradigm of education from the purpose of education to contents and methods, based on AI, are urgently needed. Research on AIED needs to be further accelerated, such that AI-based education can be established early.

Next, international collaboration should be encouraged for research on AIED (see Figures 3 and 4). The average collaboration rate of the top 40 countries with high international collaboration rates was 34\%. Although the United States plays a central role in 
international collaboration, the proportion of collaborative papers was not high, at 18.83\%. Meanwhile, Canada played an important role in international collaboration in the AIED field, as both the number of joint papers and the ratio of joint papers were high. Examining AIED from the perspective of international joint research and collaborative research beyond the national level is more desirable. The Organization for Economic Co-operation and Development highlighted the importance of international collaboration by providing "National AI Policies \& Strategies," an online platform for establishing and sharing AI public policies [82]. AI is a global issue. This is because AI needs to be viewed from the perspective of humankind to open the door to a sustainable future.

Moreover, research topics related to AIED should be more diverse. Eight topics were identified through topic modeling in this study (see Table 3). Topics emphasizing AI, such as Topic 6 (AI-driven edu-tech) and Topic 8 (machine learning algorithm), emerged and were confirmed to be hot topics, but specific areas of AIED were not highlighted. Of course, traditional fields of education, such as "content of teaching and learning" and "assessment and evaluation," cannot be disregarded. However, efforts are needed to redesign the educational paradigm from the perspective of AIED. For example, by classifying the learner types of AIED in consideration of the stages and characteristics of education, such as early childhood education, elementary and secondary education, higher education, and lifelong education, customized education, should be carried out. Learning areas, such as mathematics, science, language learning, and music, will need to be restructured based on AI. There is a need to expand research on AIED in fields directly related to AI, such as statistics, mathematics, computational physics, computers, semiconductor design, and neurophysiology. In addition, in terms of the learning method, exploratory learning using AI, writing analysis, mentoring, and learning analysis, should be expanded. Specifically, fields that understand AI, such as AI literacy and AI ethics, and fields that use AI educationally, such as ITS, DBTS, and ELE, along with research on education for fostering AI experts, should be more active areas.

Finally, in-depth research that directly applies AI algorithms and technologies to education should be further promoted. The keywords "artificial intelligence," "machine learning," and "deep learning" rarely appear in the keywords and topics presented in this study. Artificial intelligence-essential words, such as "supervised learning," "unsupervised learning," "reinforcement learning," "chatbots," "artificial neural networks," "virtual reality," and "augmented reality", are not often observed in AIED. This implies that AI algorithms and technologies have not yet been fully utilized in the AIED. For the development of AIED, education-based AI research that examines AI from an educational perspective, beyond simply using AI application services, should be strengthened. This is because we have entered an era in which education without AI cannot exist.

\section{Limitations}

This study had certain limitations in terms of the study subjects. A total of 5035 papers on AIED were extracted and analyzed in two categories related to education in the Web of Science database, but it cannot be said that it covers all papers on AIED. Additionally, it is has not considered other databases such as Scopus. Furthermore, the study could not address studies related to books and research reports, since it only targeted academic papers. Therefore, the scope of the study subjects may be limited.

\section{Conclusions}

This study was conducted in order to understand the impact of AI on education by analyzing international research trends in AIED and estimating the direction of future education. We derived key research topics and analyzed AIED research trends, such as changes in research topics over time and the state of national collaboration using frequency analysis, network analysis, and topic modeling. A total of 5035 AIED-related papers were extracted from the Web of Science database and analyzed using the LDA method. Over the past 20 years, the number of papers on AIED has increased. Particularly, the 
explosive increase since 2015 indicates that the impact of AI on education is becoming more significant. Although international collaboration is underway for research, it should be further activated, given the impact of AI on education. Eight topics, such as "changes in the content of teaching and learning," were derived using the LDA algorithm, and AIED research trends that are being explored worldwide were identified. Using a linear regression model, three hot topics, such as "AI-driven edu-tech," and two cold topics, such as "feedback on assessment and evaluation," were identified, while trend changes were confirmed for each research topic. Through the topic modeling analysis, it was identified that the research topic on AIED should be further diversified to cover the specific areas of AIED. Moreover, there was a clear pattern that the keywords and topics presented in this study have not yet escaped from the traditional field of education. Thus, in-depth research that directly applies AI algorithms and technologies to education should be further promoted.

$\mathrm{AI}$ is now everywhere and is changing human civilization. It is also becoming a key engine of revolutionary change in the field of education. AI is making us rethink the purpose of education, restructuring the content of education, and innovating new ways of teaching. Knowledge transfer-based public education is losing its place and personalized creative convergence education is gaining ground. The traditional curriculum is also changing based on AI. Mentoring using AI tutors and learning using chatbots is becoming commonplace. This is AIED, a transformative effort to redesign everything in education based on AI.

AIED has a long way to go, and research is only in its infancy. Direction needs to be agreed upon by defining the concept of AIED and unifying the related terms. The research contents of AIED need to be diversified and research methods need to be expanded. Generating the results of meaningful research that can be used for education is important. Trends in international research on AIED revealed in this study will provide a reference for exploring the direction of AIED research in the future. It is expected that various AIED studies that create new AI-based education will be conducted.

Author Contributions: Conceptualization, S.P.; methodology, N.K.; software, N.K.; validation, S.P. and N.K.; formal analysis, S.P.; investigation, S.P. and N.K.; data curation, N.K.; writing-original draft preparation, S.P. and N.K.; writing-review and editing, S.P. and N.K.; visualization, N.K.; supervision, N.K.; project administration, S.P.; funding acquisition, S.P. and N.K. All authors have read and agreed to the published version of the manuscript.

Funding: This work was supported by the National Research Foundation of Korea (NRF) grant funded by the Korea government (MSIT) (No. 2018R1D1A1B07047487 and No. 2021R1F1A1050602).

Institutional Review Board Statement: Not applicable.

Informed Consent Statement: Not applicable.

Data Availability Statement: The data presented in this study are available on request from the corresponding author.

Conflicts of Interest: The authors declare no conflict of interest.

\section{References}

1. OECD. Artificial Intelligence in Society; OECD Publishing: Paris, France, 2019; pp. 47-80.

2. McCarthy, J.; Minsky, M.L.; Rochester, N.; Shannon, C.E. A proposal for the dartmouth summer research project on artificial intelligence, August 31, 1955. AI Mag. 2006, 27, 12-14.

3. OED. Artificial Intelligence, n. OED Online. 2018. Available online: https://www.oed.com/viewdictionaryentry/Entry/271625 (accessed on 5 May 2021).

4. Russell, S.; Norvig, P. Artificial Intelligence: A Modern Approach, 2nd ed.; Prentice Hall: Upper Saddle River, NJ, USA, 2003.

5. Holmes, W.; Bialik, M.; Fadel, C. Artificial Intelligence in Education; Center for Curriculum Redesign: Boston, MA, USA, 2019.

6. Song, P.; Wang, X. A bibliometric analysis of worldwide educational artificial intelligence research development in recent twenty years. Asia Pac. Educ. Rev. 2020, 21, 473-486. [CrossRef]

7. Roll, I.; Wylie, R. Evolution and Revolution in Artificial Intelligence in Education. Int. J. Artif. Intell. Educ. 2016, 26, 582-599. [CrossRef] 
8. McArthur, D.; Lewis, M.; Bishary, M. The Roles of Artificial Intelligence in Education: Current Progress and Future Prospects. J. Educ. Technol. 2005, 1, 42-80. [CrossRef]

9. Hinojo-Lucena, F.J.; Aznar-Díaz, I.; Cáceres-Reche, M.P.; Romero-Rodríguez, J.M. Artificial intelligence in higher education: A bibliometric study on its impact in the scientific literature. Educ. Sci. 2019, 9, 51. [CrossRef]

10. Drigas, A.S.; Ioannidou, R.E. A review on artificial intelligence in special education. In World Summit on Knowledge Society; Springer: Berlin/Heidelberg, Germany, 2011; pp. 385-391.

11. Moreno-Guerrero, A.J.; López-Belmonte, J.; Marín-Marín, J.A.; Soler-Costa, R. Scientific development of educational artificial intelligence in Web of Science. Future Internet 2020, 12, 124. [CrossRef]

12. Yu, Z. Visualizing artificial intelligence used in education over two decades. J. Inf. Technol. Res. 2020, 13, 32-46. [CrossRef]

13. Chen, X.; Xie, H.; Zou, D.; Hwang, G.J. Application and theory gaps during the rise of Artificial Intelligence in Education. Comput. Educ. Artif. Intell. 2020, 1, 100002. [CrossRef]

14. Lee, J.H.; Wood, J.; Kim, J. Tracing the Trends in sustainability and social media research using topic modeling. Sustainability 2021, 13, 1269. [CrossRef]

15. Schmiedel, T.; Müller, O.; vom Brocke, J. Topic modeling as a strategy of inquiry in organizational research: A tutorial with an application example on organizational culture. Organ. Res. Methods 2019, 22, 941-968. [CrossRef]

16. Rose, R.; Holmes, W.; Griffiths, M.; Forcier, L.B. Intelligence Unleashed. An Argument for AI in Education; Pearson: London, UK, 2016.

17. AI4ALL. Available online: https:/ / ai-4-all.org/ (accessed on 10 May 2021).

18. Association for the Advancement of AI(AAAI). Available online: https:/ /www.aaai.org/ (accessed on 10 May 2021).

19. Touretzky, D.; Gardner-McCune, C.; Martin, F.; Seehorn, D. Envising AI for K-12: What Should Every Child Know about AI? Conf. Artif. Intell. 2019, 33, 9795-9799.

20. House of Lords. AI in the UK: Ready, Willing and Able? Select Committee on Artificial Intelligence. 2018. Available online: https:/ / publications.parliament.uk/pa/ld201719/ldselect/ldai/100/100.pdf (accessed on 10 May 2021).

21. Elements of AI. Available online: https://www.elementsofai.com/ (accessed on 10 May 2021).

22. Artificial Intelligence Experimental Textbook. Available online: https://item.jd.com/12461281.html (accessed on 10 May 2021).

23. Ministry of Science and ICT. National Strategy for Artificial Intelligence; Ministry of Science and ICT: Sejong, Korea, 2019.

24. MATHia. Available online: https://www.carnegielearning.com/solutions/math/mathia/ (accessed on 10 May 2021).

25. AutoTutor. Available online: https://www.memphis.edu/iis/projects/autotutor.php (accessed on 10 May 2021 ).

26. Graesser, A.C. Learning, thinking, and emoting with discourse technologies. Am. Psychol. 2011, 66, 746-757. [CrossRef]

27. Hsu, J.F.J.; Chapelle, C.A.; Thompson, A.D. Exploratory learning environments: What are they and do students explore? J. Educ. Comput. Res. 1993, 9, 1-15. [CrossRef]

28. Ben-Naim, D.; Marcus, N.; Bain, M. Visualization and analysis of student interaction in an adaptive exploratory learning environment. In Proceedings of the 1st International Workshop on Intelligent Support for Exploratory Environment, Maastricht, The Netherlands, 17 September 2008.

29. Fractions Lab. Available online: https:/ /www.italk2learn.com/ (accessed on 10 May 2021).

30. Betty's Brain. Available online: https:/ / wp0.vanderbilt.edu/oele/bettys-brain/ (accessed on 10 May 2021).

31. Tencent Research Institute. Artificial Intelligence: A National Strategic Initiative; Palgrave MacMillan: New York, NY, USA, 2020.

32. Kim, Y. Global Trend of AI Talent Development Policy in Major Countries. Mon. Softw. Oriented Soc. 2019, 62, 29-36.

33. Ministry of Education. The Plan to Foster the AI Teachers; Ministry of Education: Sejong, Korea, 2019.

34. Yan, E.; Ding, Y.; Milojević, S.; Sugimoto, C.R. Topics in dynamic research communities: An exploratory study for the field of information retrieval. J. Informetr. 2012, 6, 140-153. [CrossRef]

35. Lee, H.; Kang, P. Identifying core topics in technology and innovation management studies: A topic model approach. J. Technol. Transf. 2018, 43, 1291-1317. [CrossRef]

36. Daenekindt, S.; Huisman, J. Mapping the scattered field of research on higher education. A correlated topic model of 17,000 articles, 1991-2018. Higher Educ. 2020, 80, 1-17. [CrossRef]

37. Hong, S.; Park, T.; Choi, J. Analyzing Research Trends in University Student Experience Based on Topic Modeling. Sustainability 2020, 12, 3570. [CrossRef]

38. De Battisti, F.; Ferrara, A.; Salini, S. A decade of research in statistics: A topic model approach. Scientometrics 2015, 103, 413-433. [CrossRef]

39. Sharma, D.; Kumar, B.; Chand, S. A trend analysis of machine learning research with topic models and Mann-Kendall test. Int. J. Intell. Syst. Appl. 2019, 11, 70-82. [CrossRef]

40. Kang, H.J.; Kim, C.; Kang, K. Analysis of the trends in biochemical research using Latent Dirichlet Allocation (LDA). Processes 2019, 7, 379. [CrossRef]

41. Xiong, H.; Cheng, Y.; Zhao, W.; Liu, J. Analyzing scientific research topics in manufacturing field using a topic model. Comput. Ind. Eng. 2019, 135, 333-347. [CrossRef]

42. Blei, D.M.; Ng, A.Y.; Jordan, M.I. Latent dirichlet allocation. J. Mach. Learn. Res. 2003, 3, 993-1022.

43. Tran, B.X.; Vu, G.T.; Ha, G.H.; Vuong, Q.H.; Ho, M.T.; Vuong, T.T.; La, V.-P.; Ho, M.-T.; Nghiem, K.-C.P.; Nguyen, H.L.T.; et al. Global evolution of research in artificial intelligence in health and medicine: A bibliometric study. J. Clin. Med. 2019, 8, 360. [CrossRef] 
44. Loper, E.; Bird, S. Nltk: The natural language toolkit. arXiv 2002, arXiv:cs/0205028.

45. May, C.; Cotterell, R.; Van Durme, B. An analysis of lemmatization on topic models of morphologically rich language. arXiv 2016, arXiv:1608.03995.

46. Schofield, A.; Mimno, D. Comparing apples to apple: The effects of stemmers on topic models. Trans. Assoc. Comput. Linguist. 2016, 4, 287-300. [CrossRef]

47. Honnibal, M.; Montani, I. spaCy 2: Natural language understanding with Bloom embeddings, convolutional neural networks and incremental parsing. To Appear 2017, 7, 411-420.

48. Borgatti, S.P. Centrality and network flow. Soc. Netw. 2005, 27, 55-71. [CrossRef]

49. Kim, J.; Kang, P. Analyzing international collaboration and identifying core topics for the "internet of things" based on network analysis and topic modeling. Int. J. Ind. Eng. 2018, 25, 349-369.

50. Chang, J.; Boyd-Graber, J.; Wang, C.; Gerrish, S.; Blei, D.M. Reading tea leaves: How humans interpret topic models. Adv. Neural Inf. Process. Syst. 2009, 22, 288-296.

51. Röder, M.; Both, A.; Hinneburg, A. Exploring the space of topic coherence measures. In Proceedings of the Eighth ACM International Conference on Web Search and Data Mining, Shanghai, China, 2-6 February 2015; pp. $399-408$.

52. Agrawal, R.; Imieliński, T.; Swami, A. Mining association rules between sets of items in large databases. In Proceedings of the 1993 ACM SIGMOD International Conference on Management of Data, Washington, DC, USA, 25-28 May 1993 ; pp. $207-216$.

53. Borgelt, C. Frequent Item Set Mining. WIREs Data Min. Knowl. Discov. 2012, 2, 437-456. [CrossRef]

54. Borgelt, C.; Kruse, R. Induction of association rules: Apriori implementation. In Compstat; Physica Verlag: Heidelberg, Germany, 2002; pp. 395-400.

55. Harris, C.J.; Krajcik, J.S.; Pellegrino, J.W.; DeBarger, A.H. Designing knowledge-in-use assessments to promote deeper learning. Educ. Meas. Issues Pract. 2019, 38, 53-67. [CrossRef]

56. Cope, B.; Kalantzis, M. Big data comes to school: Implications for learning, assessment, and research. AERA Open 2016, 2, 2332858416641907. [CrossRef]

57. Graesser, A.C. Evolution of advanced learning technologies in the 21st century. Theory Pract. 2013, 52, 93-101. [CrossRef]

58. Liao, S.N.; Zingaro, D.; Thai, K.; Alvarado, C.; Griswold, W.G.; Porter, L. A robust machine learning technique to predict low-performing students. ACM Trans. Comput. Educ. 2019, 19, 1-19. [CrossRef]

59. Jain, G.P.; Gurupur, V.P.; Schroeder, J.L.; Faulkenberry, E.D. Artificial intelligence-based student learning evaluation: A concept map-based approach for analyzing a student's understanding of a topic. IEEE Trans. Learn. Technol. 2014, 7, 267-279. [CrossRef]

60. Chen, P.S.D.; Lambert, A.D.; Guidry, K.R. Engaging online learners: The impact of Web-based learning technology on college student engagement. Comput. Educ. 2010, 54, 1222-1232. [CrossRef]

61. Hew, K.F.; Hu, X.; Qiao, C.; Tang, Y. What predicts student satisfaction with MOOCs: A gradient boosting trees supervised machine learning and sentiment analysis approach. Comput. Educ. 2020, 145, 103724. [CrossRef]

62. García, P.; Amandi, A.; Schiaffino, S.; Campo, M. Evaluating Bayesian networks' precision for detecting students' learning styles. Comput. Educ. 2007, 49, 794-808. [CrossRef]

63. Flogie, A.; Abersek, B. Transdisciplinary Approach of Science, Technology, Engineering and Mathematics Education. J. Balt. Sci. Educ. 2015, 14, 779-790.

64. Garcia, I.; Pena, M.I. Machine translation-assisted language learning: Writing for beginners. Comput. Assist. Lang. Learn. 2011, 24, 471-487. [CrossRef]

65. Niño, A. Machine translation in foreign language learning: Language learners' and tutors' perceptions of its advantages and disadvantages. ReCALL 2009, 21, 241-258. [CrossRef]

66. Martín-Gutiérrez, J.; Mora, C.E.; Añorbe-Díaz, B.; González-Marrero, A. Virtual technologies trends in education. Eurasia J. Math Sci. Technol. Educ. 2017, 13, 469-486.

67. Jara, C.A.; Candelas, F.A.; Puente, S.T.; Torres, F. Hands-on experiences of undergraduate students in Automatics and Robotics using a virtual and remote laboratory. Comput. Educ. 2011, 57, 2451-2461. [CrossRef]

68. Berman, N.B.; Durning, S.J.; Fischer, M.R.; Huwendiek, S.; Triola, M.M. The role for virtual patients in the future of medical education. Acad. Med. 2016, 91, 1217-1222. [CrossRef]

69. Shorey, S.; Ang, E.; Ng, E.D.; Yap, J.; Lau, L.S.T.; Chui, C.K. Communication skills training using virtual reality: A descriptive qualitative study. Nurse Educ. Today 2020, 94, 104592. [CrossRef]

70. Lykourentzou, I.; Giannoukos, I.; Nikolopoulos, V.; Mpardis, G.; Loumos, V. Dropout prediction in e-learning courses through the combination of machine learning techniques. Comput. Educ. 2009, 53, 950-965. [CrossRef]

71. Tan, M.; Shao, P. Prediction of student dropout in e-Learning program through the use of machine learning method. Int. J. Emerg. Technol. Learn. 2015, 10, 11-17. [CrossRef]

72. Griffiths, T.L.; Steyvers, M. Finding scientific topics. Proc. Natl. Acad. Sci. USA 2004, 101, 5228-5235. [CrossRef]

73. Jensen, J.L.; Kummer, T.A.; Godoy, P.D.D.M. Improvements from a flipped classroom may simply be the fruits of active learning. CBE Life Sci. Educ. 2015, 14, ar5. [CrossRef] [PubMed]

74. Akyol, Z.; Garrison, D.R. Understanding cognitive presence in an online and blended community of inquiry: Assessing outcomes and processes for deep approaches to learning. Br. J. Educ. Technol. 2011, 42, 233-250. [CrossRef]

75. Xing, W.; Du, D. Dropout prediction in MOOCs: Using deep learning for personalized intervention. J. Educ. Comput. Res. 2019, 57, 547-570. [CrossRef] 
76. Liu, M.; McKelroy, E.; Kang, J.; Harron, J.; Liu, S. Examining the use of Facebook and Twitter as an additional social space in a MOOC. Am. J. Distance Educ. 2016, 30, 14-26. [CrossRef]

77. Erhel, S.; Jamet, E. Digital game-based learning: Impact of instructions and feedback on motivation and learning effectiveness. Comput. Educ. 2013, 67, 156-167. [CrossRef]

78. Xu, L.; Huang, D.; Tsai, W.T. Cloud-based virtual laboratory for network security education. IEEE Trans. Educ. 2013, 57, 145-150. [CrossRef]

79. Ong, S.K.; Mannan, M.A. Virtual reality simulations and animations in a web-based interactive manufacturing engineering module. Comput. Educ. 2004, 43, 361-382. [CrossRef]

80. McNamara, D.S.; Crossley, S.A.; Roscoe, R.D.; Allen, L.K.; Dai, J. A hierarchical classification approach to automated essay scoring. Assess. Writ. 2015, 23, 35-59. [CrossRef]

81. Huang, S.; Fang, N. Predicting student academic performance in an engineering dynamics course: A comparison of four types of predictive mathematical models. Comput. Educ. 2013, 61, 133-145. [CrossRef]

82. OECD. National AI Policies \& Strategies. Available online: https://www.oecd.ai/dashboards (accessed on 10 May 2021). 